\title{
Effects of Modality and Redundancy Principles on the Learning and Attitude of a Computer-Based Music Theory Lesson among Jordanian Primary Pupils
}

\author{
Osamah (Mohammad Ameen) Ahmad Aldalalah \\ School of Educational Studies, Universiti Sains Malaysia \\ Minden 11800, Penang, Malaysia \\ Tel: 60-6-777-7777 E-mail: usm.osamah@gmail.com \\ Soon Fook Fong (Corresponding author) \\ School of Educational Studies, Universiti Sains Malaysia \\ Minden 11800, Penang, Malaysia \\ Tel: 60-4-653-2968 E-mail: sffong05@gmail.com
}

\begin{abstract}
The purpose of this study was to investigate the effects of modality and redundancy principles on the attitude and learning of music theory among primary pupils of different aptitudes in Jordan. The lesson of music theory was developed in three different modes, audio and image (AI), text with image (TI) and audio with image and text (AIT). The study sample consisted of 405 third-grade pupils. Analyses of covariance (ANCOVA) and Post hoc were carried out to examine the main effects as well as the interaction effects of the independent variables on the dependent variables. The findings of this study showed that pupils using the AI mode performed significantly better than those in the TI mode. Pupils using the TI mode did not perform significantly better than those in the AIT mode. There were no significant differences in the preference or dislikes towards the three modes of courseware. Overall, the modality and redundancy principles need to be considered in the design and development of music theory learning so as to promote better learning.
\end{abstract}

Keywords: Modality and redundancy principles, Music theory, Cognitive theory of multimedia learning, Cognitive load theory

\section{Introduction}

Music theory is the field of study that deals with how music works. It basically addresses the language and notation of music in which music can be read and written. It helps to identify the different patterns and structures revealed in the techniques of composers, across or within genres, styles, or historical periods (Nosir, 1980). Music theory can be considered as a universal language as it has a universal context and notations (Chew, 2005).

Since music theory concentrates on how music notation is written (i.e. the elements of the notation) it provides a form of communication for musicians to express their musical concepts (Aldalalah, 2003). However, music theory also includes underlying concepts of music such as the structure, the organization and the history (Smith, 2009). These underlying concepts contribute towards building the basic knowledge in music notation and understanding the evolving stages in music as well as the way the notation is used in different circumstances. Accordingly, the theory of music includes the following basics:

- The elements of standard music notation such as Staves, Clefs, note lengths, note pitches, key signatures, time signatures, beats and bars (i.e. measures).

- Underlying concepts such as scales, keys, intervals and rhythm.

- Advanced elements such as dynamics and phrasing (notated with slurs).

- Advanced concepts such as the history of notation and the form of music theory.

The studies conducted by Wilson (2005) Mcvay (2004) and Guderian (2008) have found that many students encounter difficulty in reading music theory and, hence, have difficulty in learning music. Many Arab countries are reviewing their music curriculum to enhance music theory in music education. Jordan is one of the countries that is currently undergoing a review of the music education curriculum (Yagmour, 2007). Alwan (2008) reported that music theory is being taught in Jordanian schools using only traditional methods and not supported by 
computer-based tools. Ramzy \& Alabdaly (2005) found that most pupils indicated that these conventional teaching methods were not helpful in the learning process and they could not remember or understand music theory in depth. In addition, the students could not apply music theory correctly. From a preliminary survey conducted by the researchers (as a member of the national team to develop music curriculum at the Ministry of Education in Jordan) among 53 primary school music teachers in Irbid Governorate (Jordan), it was found that $81 \%$ of the teachers indicated that they faced problems in the teaching and learning of music theory effectively.

Obeidat (2008) reported that even though highly competent music teachers in the classroom use audio, image and text in teaching and learning of music theory, the students performance was still very low. To deal with the problem of weaknesses in understanding music theory, Aldalalah (2003) and Yagmor, \& Aldalalah (2007) suggested approaching the problem through designing a computer based learning program. The results showed a marked improvement in the students' level of understanding. In this regard, Obeidat (2003) and Dyabat (2007) conducted a study to investigate the effects of using computerized instructional programs in learning music theory. The results showed that computer-based learning significantly assisted the students in learning music theory. Thus it is apparent from the review of these studies that the traditional way of learning music theory audio, image and text may not enhance or facilitate the learning process. According to Clark \& Mayer (2008), redundant onscreen text in a multimedia presentation may overload the visual channel. This is because the image comes into the pupils' cognitive system through the eyes in order to be processed in the visual channel. The printed text too enters through the eyes and must be processed in the visual channel. Due to the limited cognitive resources in the visual channel that have to be utilized to process both the image and the text, an overload in the visual channel may occur.

The researchers contend that the appropriate application of modality and redundancy of instructional design principles in computer-based learning could effectively enhance the learning of music theory. In this respect, the modality and redundancy principles offer a feasible approach if they are integrated into computer-based learning as the instructional design. According to Sweller, (1999) and Mayer's theory of multimedia learning (Mayer, 2001), replacing visual text with spoken text (the modality effect) may increase the effectiveness of instructional multimedia. Images are transported along the visual channel while the narration text is transported along the auditory channel resulting in an increase in the working capacity of the memory resulting in greater ease of learning (Seufert, Schu \& Nken, 2009). Furthermore, onscreen text accompanied with images in a multimedia presentation may overload the visual channel. In addition, using image, onscreen text and audio narration in which the audio repeats the text will also cause an overload due to the redundancy in the presented material. This extra effort or attention needed by the students to handle such information streams is considered as a disadvantage for the acquisition of both the words and pictures (Clark \& Mayer, 2008).

\section{Modality principle}

Moreno \& Mayer (1999) suggested that pictures should go together with a synchronized auditory explanatory recitation rather than a synchronized explanatory text, (see Figure 1).Mayer \& Mereno (1998) and Alherish, Alababneh \& Aldalalah (2005) found that the learner's understanding when watching animated images on a certain phenomenon (the lightning phenomenon) accompanied with an auditory explanation is much better than the learner's understanding when watching animated images on the same phenomenon while verbally reading an onscreen-text explanation. At the same time, this principle is in tandem with the cognitive learning theory using multimedia techniques. The cognitive learning theory suggests that reading an onscreen-text along with animated pictures will result in interference in the rendered information especially when this information is to be processed verbally (Mayer, 2010). However, this will add more load on the visual working memory because both are addressed in the form of verbal memory and in visual approach while the auditory text is processed in the verbal model and audio working memory (Harskamp, Mayer \& Suhre, 2007; Aldalalah \& Fong, 2008). Furthermore, animated images are processed in the visual model, thus, providing an auditory text along with watching an explanatory film that does not overlap (Wouters, Paas, Jeroen \& Merrienboer, 2009). Therefore, this also fits the modality principle by combining the visual channel for graphical material and the verbal channel for the explanation of this material to increase the working memory capacity effectiveness and facilitate learning (Moreno, 2006).

\section{Redundancy Principle}

There is now much evidence to suggest that redundant material imposes a significant extraneous cognitive load that has negative outcomes for learning and understanding (Sweller 1999). Redundant material interferes with learning rather than proving to be advantageous or even neutral when acquiring new information. By eliminating redundant information the load on working memory is considerably reduced, thus facilitating better learning. 
The Redundancy Effect occurs when learners are required to attend to or engage in activities that are irrelevant to the task at hand (Sweller, 2005). The effect has been shown to interfere with the core material to be learned due to the extraneous load imposed on working memory (Chandler \& Sweller, 1991). Increasing working memory load by simultaneously processing redundant information with essential information that needs to be learned, results in the transfer of information into long-term memory becoming problematic. The Redundancy Effect is associated with materials or information that can be understood in isolation of each other (Sweller \& Chandler 1994). Information presented in multiple forms, or information that is unnecessarily elaborated is representative of redundancy (Sweller, Paas \& Renkl, 2003).

Kalyuga, Chandler \& Sweller (2004) again demonstrated the redundancy effect in a task involving listening and reading identical text in a series of experiments involving training materials for technical apprentices. The redundancy effect has been described in the past as counter-intuitive (Sweller, 2006) as it is often assumed that an abundance of information is advantageous to the learner. Cognitive load theory states otherwise asserting that an overload on working memory inhibits learning. Pictures are an additional and unnecessary load for the working memory to process when learning to read, and therefore redundant. Pictures are very likely to distract the child from the text thereby drawing on working memory resources that could be otherwise used for the processing and storing of core information associated with the decoding process (Diao \& Sweller, 2007).

The Redundancy Principle suggests improving multimedia presentation by presenting animation along with concurrent recitation and on-screen text (Moreno, R. \& Mayer, 2002). To allow the students to choose the format that goes well with their learning style, the above principle suggests presenting the same words in two formats (Kalyuga, Chandler, \& Sweller, 1999; Mayer, 2005). Therefore, the students can pay more attention to the auditory words if their learning is better compared to other learning methods. Adding on-screen text to a recited animation can be justified by better containing individual learning styles. However, the cognitive theory of multimedia learning as discussed previously, suggested that the added on-screen text will interfere with the animation of cognitive resources in the visual-pictorial channel as illustrated in creating what Sweller (1999) calls a split-attention effect. Students will have to put more effort and pay more attention visually to both the printed words and the animated pictures as illustrated in Figure 2.

Multimedia learning incorporates the presentation of visual materials (such as animations, video, or graphics) along with a synchronized text and audio (Moreno \& Mayer, 2000). However, the redundancy principle indicates that learning and its achievements of the student using animation and recitation is much better compared to the learning and its achievements of the student using animation, recitation, and text, especially if the visual information is presented concurrently with the vocal information (Mayer \& Moreno, 1997). At the same time, simultaneous presentations of printed text explanations and auditory recitation of the same information would be inappropriate as they exhaust the student's cognitive abilities of the working memory and upset learning (Clark \& Mayer, 2003) because the printed text representation will trouble the visual channel. This visual channel will instead have to manipulate the textual and graphical information, especially, when the text is redundant and auditory narrations are duplicated (Muthukumar, 2005).

The redundancy effect will occur if the information that can be completely understood in isolation (as either visual or auditory information) is presented to both channels and is the same information. However, incorporating the redundant information in both working memories can eventually increase the cognitive load. This results in a split-attention dilemma. This dilemma varies depending on the learner's experience. However, a diagram with text may be favorable for beginners because they need to incorporate the text to the diagram to make more sense for them. At the same time, the same strategy might become redundant for a more experienced learner and the diagram alone makes more sense for them (ie. computer manuals that have minimal text and plenty of diagrams). In summary, the redundancy effect is that "less is often more" in learning and that cognitive capacity is over excised (Sorden, 2005).

\section{Attitudes toward Computer in Education}

Computers are all the time more general, influencing many aspects of our social and work lives, as well as several of our free time activities (Al-Mallah, 2005). As more responsibilities engage human computer interaction, computer skills and information have grown to be more positively related with both occupational and personal achievement (Silku, 2009). Consideration of user attitude is an integral part of educational computing research. It is seen not only initial acceptance of IT but also future behavior regarding computers (Selwyn, 1999). Students' attitudes towards computers form a fundamental basis for both participation and subsequent achievement in information technology activities (Jones \& Clarke 1994). Students' proclivity to use the technology has long been 
regarded as an significant part of educational computing and an awareness of attitudes towards computers (Kilic, 2001).

\section{Research Questions}

The research questions that drive this study are as follows:-

1) Will pupils using the Audio, Images (AI) mode attain significantly higher post test score (PTS) than pupils using the Text, Images (TI) mode?

2) Will pupils using the Text, Images (TI) mode attain significantly higher post test score (PTS) than pupils using the Audio, Images, Text (AIT) mode?

3) Will pupils using the Audio, Images (AI) mode attain significantly higher attitude scores (AS) than pupils using the Text, Images (TI) mode?

4) Will pupils using the Text, Images (TI) mode attain significantly higher attitude scores (AS) than pupils using the Audio, Images, Text (AIT) mode?

\section{Methods}

\subsection{Population Sample}

The population of this study comprised all third grade primary pupils (2263) enrolled in the ALKORAH educational directorate in Irbid Governorate (Jordan) in the second semester for the 2008/2009 academic year. The sample consisted of 405 pupils who studied in third-grade classes and were randomly selected from six different primary co-educational schools. According to Gay and Airasian (2003) "all the individuals in the defined population have equal and independent chance of being selected". The six schools were also randomly selected from the primary schools where music was taught in heterogeneous classes with no grouping or ability tracking.

\subsection{Experimental Condition}

The pupils' distribution within the treatment groups was conducted randomly. Then the treatment groups were exposed to the treatment consecutively. The three treatment groups are as follows:

- First treatment group: computer-based learning presented in audio and text (AI)

- Second treatment group: computer-based learning presented in text and image (TI)

- Third treatment group: computer-based learning presented in audio, image and text (AIT)

\subsection{Instruments}

The music achievement test that was administered on the participants of the three groups in this study is adapted from the music theory competency test developed by the researcher. The music theory competency test consisted of 15 recall (remembering) and 15 understanding items

\subsubsection{Music achievement test Reliability:}

To ensure the reliability of the music achievement test, the researchers checked the reliability of the instrument with a Test-Retest (Tuckman, 1999) where it was applied on the pilot study samples. The 30 items were divided into two parts; the reliability of the test questions was calculated using the Cronbach Alpha procedure to calculate the internal consistency. The Cronbach Alpha of the first and second parts was 0.81 and 0.82 respectively. The Cronbach Alpha of the test was 0.80 . All of them were found to be reliable. The internal consistency of the first part was 0.86 and that of the second part was 0.88 . Overall, internal consistency of the parts was 0.93 .

\subsubsection{Difficulty and Discrimination Coefficients}

Difficulty values ranged from $0.31-0.66$, and discrimination coefficients ranged from $0.45-0.98$; both were found to be acceptable for the purposes of this study

\subsubsection{Attitude Questionnaire}

Based on the literature review on the trends in using computer in teaching pupils, the researchers adopted and adapted the attitude test from (Al Dalalah, 2003) (Refer to appendix Ca). The survey was confirmed and brought to the attention of experts in educational technology, curricula, evaluation and assessment and primary education in Jordan. The researchers adopted and adapted the attitude test from (Al Dalalah, 2003) The researchers has modified this survey to meet the needs of this study where it has been reduced to 20 items. Each item is followed by a set of three possible answers, that is, Agree, Neither, and Disagree. This is in line with the opinions of experts who have taken into consideration the suitability of the pupils (sample study).

\subsubsection{Attitude Questionnaire Reliability}

The pilot study consisted of 212 participants. The researchers used Test-Retest to check the reliability of the instrument. The reliability coefficient of this instrument (The Arabic version) was computed by the 
implementation of Cronbach Alpha whereby it was 0.79 for the whole scale. The internal consistency in this instrument (Arabic version) was 0.83 .

\subsubsection{Instruments Validity}

Validity of the instruments are important aspects that should be taken into account when conducting a research. Validity consists of two different aspects that is face and content validity. According to Gay and Airasian (2000) face validity relates to " the degree to which a test appears to measure what it claims to measure". Face validity was judged by a panel of experts in the field of education and music. Content validity refers to the "degree to which a test measures an intended content area " (Gay and Airasian, 2000). Content validity of the instruments in this research was justified by the panel. The panel of experts comprised 2 specialists in the field of educational technology; 1 specialist in curricula and teaching methods, 2 specialists in music education, a supervisor of music activity in the ALKORAH education directorate; 2 members of the National Team For The Development of Music Curriculum, 2 specialists in Psychology, 2 specialists in primary education, 1 specialist in computer science, 1 specialist in measurement and evaluation, and 2 music teachers who have Masters degrees and a remarkable teaching experience in Jordan, each teacher has a minimum of four years of teaching experience in the Jordanian Ministry of Education. The instruments were evaluated during and after the development of the research study. The feedback and comments received from the panel of experts were employed to establish the necessary clarifications, changes, and modifications before and after piloting the study.

\subsection{Study Design}

The research design of this study is based on the concept of the cognitive theory (Mayer, 2001). This study followed the quasi experimental method to measure the impact of different multimedia programs on the total achievement of the third grade pupils in the music classes according to the modality and redundancy principles of cognitive theory.

\subsection{Research Variables}

The present research contains three types of variables (independent, dependent and moderating variables) that are presented as follows:

\subsubsection{Independent Variables}

The independent variables in this study were the three modes of presentation:

- Multimedia computer-based learning courseware with music theory presented in audio and text (AI)

- Multimedia computer-based learning courseware with music theory presented in text and image (TI)

- $\quad$ Multimedia computer-based learning courseware with music theory presented in audio, image and text (AIT)

6.5.2. Dependent Variables

- $\quad$ Post Test Scores (learning)

- Attitude

\section{Results}

The analyses of the collected data were carried out through various statistical techniques such as the $t$-test, ANCOVA, ANOVA, simple and multiple regressions. The data were compiled and analyzed using the Statistical Package for the Social Science (SPSS 16) for Windows computer software.

\subsection{Measure of Relationship between Pre-test Scores and Post-test Scores}

Table 1 shows the degree of relationship between the pretest score and post-test score. A correlation coefficient of $R=0.627^{* *}$ indicates a high positive relationship between the two variables.

\subsection{Testing the three groups' equivalence}

The purpose of the pre-experimental study was to test the assumption that the participants across the three groups were equivalent in their remembering and understanding of the music theory unit for third grade primary pupils. To achieve this purpose, a pre-test that measures pre-music theory was conducted before the beginning of the study. To examine the equality of treatment mode on the pre-scores, the ANOVA procedure was used (Table 2). Table 2 presents the results of the ANOVA test. The values F $(2,402)=2.349$, Mean Square $=13.519$, and $\mathrm{p}=.097$ showed that there is no significant difference in the pre- test scores in the various treatment groups. This means that the three groups have the same level of prior knowledge of the unit on music theory for third grade primary pupils. 


\subsection{Testing Homogeneity of Variances for the Variables in the Pre-test}

The results from Levene's Test for homogeneity of variance by comparing the dependent variables across the four groups for Treatments indicated that homogeneity of variance was met by all the dependent variables. As $p>0.05$ for all variables, the results show that the groups were homogenous as shown in Table 3.

\subsection{Testing of Normality of Distributed Pre-test}

A skewness range from 0.039 to 0.866 was well below the suggested level of the absolute value of 3.0. In addition, a kurtosis range from 0.257 to 0.857 revealed that the variables are not overly peaked and well below the absolute value of 10.0 as suggested by Chan (2003). Thus, the presented values reveal that the variables are normally distributed and have met the criteria for further analysis as shown in Table 4.

\subsection{Testing Homogeneity of Variances for the Variables in the Post-test}

The results from Levene's Test for homogeneity of variance by comparing the dependent variables across the four groups for each variable indicated that homogeneity of variance was met by all the dependent variables. As $\mathrm{p}>$ 0.05 for all the variables, the results show that the groups were homogenous as shown in Table 5 .

\subsection{Testing of Normality of Distributed Post-test}

A skewness range from -0.193 to 0.906 was well below the suggested level of the absolute value of 3.0. In addition, a kurtosis range from -1.044 to 1.137 revealed that the variables are not overly peaked and well below the absolute value of 10.0 as suggested by Chan (2003). Thus the presented values reveal that the variables are normally distributed and have met the criteria for further analysis as shown in Table 6.

\subsection{Description of the Post-test Scores of Pupils in Various Treatment Groups}

Comparison was made between group AI and TI, and between group TI and AIT based upon the mean of the post-test scores (Table 7). It showed a difference between the means of the post-test scores for groups using the AI mode and TI mode. The mean of post test scores for groups using the AI mode (25.17) was higher than the mean of post-test scores for the group using the TI mode (16.82). Moreover, it showed a difference between the means of the post-test scores for the groups using the TI and AIT modes. The mean of the post-test scores for the group using the TI mode (16.82) was higher than the mean of the post-test scores for the group using the AIT mode (16.63).

\subsection{ANCOVA of Post-test Scores of Pupils in Various Treatment Groups}

In order to reduce the statistical error, the pre-test scores were used as the covariate variable and a comparison was made among the three groups (AI, TI \& AIT) using the ANCOVA procedure (Table 8). Table 8 indicated the results of ANCOVA test of statistical significance on the differences observed in the mean score of the post-test for the various treatment groups with $\mathrm{F}(2,401)=472.989$, Mean Square $=2600.673$ and $\mathrm{p}=0.000$. Therefore, these differences in the post-test scores among the three groups were significant.

The ANCOVA results of comparing pupils across the three groups (AI, TI \& AIT) on the dependent variables indicated that there were statistically significant differences among pupils in the groups on the dependent variable. Therefore, the researchers further investigated the univariate statistics results (analysis of covariance ANCOVA) by performing a post hoc pairwise comparison using the LSD command for dependent variable in order to identify significantly where the differences in the means resided. Table 9 is a summary of the post hoc pairwise comparisons between pupils' learning across the three groups. Table 8 and Table 9 show that there are statistical differences among the pupils' post-test scores in the three groups. There are statistical differences between the pupils' post- test scores in the AI and TI groups in music theory learning.. Finally, there are no statistical differences between pupils' learning in the TI and AIT groups' post-test scores. The differences are presented below.

The AI (Mean $=25.17, \mathrm{SD}=3.35$, ) pupils' learning significantly outperformed the TI (Mean $=16.82, \mathrm{SD}=3.77$ ) and the AIT (Mean $=16.63, \mathrm{SD}=4.33$ ). There were significant differences between pupils' learning in AI group and pupils' learning in TI group $(\mathrm{p}=0.000)$, and there were significant differences between pupils' learning in AI group and pupils' learning in AIT group $(\mathrm{p}=0.000)$. Finally there were no significant differences between pupils' learning in TI group and pupils' learning in AIT group $(\mathrm{p}=.994)$.

\section{9. $t$-test of Attitude Score of Pupils in Various Treatment Groups}

Table 10 shows the results comparing the different attitude scores of the pupils between group AI and TI. There is a difference between the means of post-test scores for group with AI and group with TI. The mean of post-test scores for group with TI (38.0567) was higher than the mean of post-test scores for group with AI (37.7891), and p $=0.270$. This shows that there is no significant difference. Moreover, it showed a difference between the means of 
post-test scores for group with TI and group with AIT. The mean of post-test scores for group with AIT (38.5294) was higher than the mean of post-test scores for group with TI (38.0567), and $p=0.655$. This indicates that the difference is not significant.

\section{Discussion}

\subsection{Modality principle and Music Theory learning}

This study found that pupils using AI mode learn better compared to pupils using the TI mode. There are several possible reasons for this result. Firstly, a possible reason for the significantly positive effect of modality principle on pupils' learning can be explained by Mayer's (2001) cognitive theory of multimedia learning. The cognitive theory of multimedia learning proposed that the human information processing system comprises dual channels, that is, one for visual processing and the other for auditory processing. When information is presented to the eye (image and text), learners begin by processing that information in the visual channel; when information is presented to the ears (audio), learners begin by processing that information in the auditory channel. According to Mayer (2001) learners have a limited capacity in the amount of information that can be processed in each channel at any one time. In this way the information processed through the two channels are balanced, that is, neither one of the channel is cognitive overloaded. The picture enters through the eyes (and is processed in the visual / pictorial channel) while the spoken word enters through the ears (processed in the auditory / verbal channel).

Secondly, it may result from the modality effect on pupils' music theory learning. The modality principle is that pupils learn more deeply from AI than from TI. According to the modality principle, pupils using the AI mode are expected to learn better than pupils using the TI mode. According to the cognitive theory of multimedia learning, the processes required for learning cannot be fully achieved when the visual channel is overloaded, that is, when pupils using the TI mode do not learn better compared to pupils using the AI mode

Thirdly, it could be that the image and text (TI) compete for limited cognitive resources in the visual channel because both enter the information processing channel through the eyes. In such a condition, visual image together with the printed written text may result in an overload in the visual channel while the auditory channel remained unused. This will affect the processing of information. Moreover, pupils using the TI mode (printed text and image) had to split their attention between the two information sources (Mayer, 2008). They had to switch their attention back and forth between the printed text and image which occupied much cognitive load to process the switching.

Fourthly, the working memory refers to an information processing system that provides temporary storage and manipulation of the information necessary for complex cognitive tasks in music theory learning. The working memory has been found to require simultaneous storage and processing of information and is therefore very important for processing musical theory by the pupils. This directly affects cognitive processing which in turn is associated with information processing system, and at the same time is affected by the pupils' processing level so that processing produces a cognitive structure with unstable knowledge that may be lost or forgotten. A pupil with a poor working memory capacity may have delayed learning of music theory. Further the AI mode processes and realigns information better and that helps maintain information retention and storage in the long-term memory.

The results from this study concur with the results reported by many studies which confirmed the effectiveness of the modality principle in learning, for example, Hamtini (2002) emphasized the use of audio facilities in instructional programs; Hirsh, Ababneh \& Aldalalah (2005) found the active roles of animation and audio in teaching third grade science; and Aldalalah \& Fong (2008) showed that the effectiveness of the working memory in learning science in Jordan depends on the modality principle. However, Wouters, Paas, Jeroen \& Merrienboer (2008); Seufert, Tze \& Nken, (2009); found that combining sounds with image reduces visual channel overload.

\subsection{Redundancy Principle and Music Theory learning}

This study found that pupils using TI mode did not learn better compared to pupils using the AIT mode. A possible reason for this result can be explained by the phenomena of cognitive overload and split attention.

Pupils using the TI mode did not significantly have better post-test scores compared to pupils using the AIT mode. According to Clark \& Mayer (2008), loading redundant onscreen text to a multimedia presentation could overload the visual channel because the image enters the pupils' cognitive system through the eyes and is processed in the visual channel, whereas the audio enters the pupils' cognitive system through the ears and is processed in the auditory channel. Since the printed text enters through the eyes and must be processed in the visual channel, and since the limited cognitive resources in the visual channel must be shared in processing both the image and the text, an overload occurs.

According to the cognitive theory of multimedia learning, learners have limited cognitive capacity in the visual and auditory channels. Pupils may pay so much attention to the printed text that they pay less attention to the 
image. When their eyes are on the printed text, the pupils cannot be looking at the image at the same time. In addition, the pupils may try to compare and reconcile the printed text with the narration text, which requires extraneous cognitive processing to learning the content. This a will result in as cognitive overload.

Split-attention effect holds that the use of materials that require pupils to split their attention between two sources of information causes a higher cognitive load on working memory and therefore impedes the learning process (Mayer \& Moreno, 2003).

In the TI and AIT mode Mayer \& Moreno (1998) states that a split-attention effect is induced if two or more sources are carried in the same channel.

Attending to multiple sources in the same channel requires more mental effort than attending to two channels, resulting in a reduced portion of the working memory available for the process of learning. Toh (2005) concluded that presenting different sources of information in the TI (for example, only visually) will result in a split-attention effect which leads to poor learning performance.

As Sweller (2005) pointed out, there is a link between cognitive load and the redundancy principle because when additional information is presented, there can be a learning decrement because of the redundancy effect. The results of this study show that when information is presented in multiple forms such as was the case in this study (AIT mode), the information may interfere with learning rather than facilitate it. Moreover, Mayer (2001) observed that if additional information is used to enhance or elaborate, and that information is fundamentally redundant, then learning can be enhanced by the exclusion of that additional information.

\subsection{Attitudes}

The results of this study indicated that primary third grade pupils possess positive attitudes with regards to all the treatment modes. Further, there were no significant differences in attitudes regarding the three treatments. The latter is attributed to the very nature of music theory, and to the interactivity allowed by computers in which the content was delivered. As experienced in everyday life, music would pass unnoticed by pupils. The three treatments in this study stimulated the pupils' attention, provided new ways of delivering the lesson, and used new stimuli and strategies based on the cognitive theory of multimedia that assimilates the human brain in dealing with data processing (Xuanxi, Fong \& Samsuddin, 2008). In light of the pupils' need, the treatments in the current study provided learners with rich, vigorous, and exciting experiences that contributed to their positive attitudes, and because the treatments are somewhat modern teaching methods, they motivated and enhanced the pupils' interests in specific fields. This makes certain cognitive activities most desirable for the pupils. Taking into account the powerful role of computers in contemporary life, the importance of learning about software packages and Information Technology advancements also boosted their positive attitudes towards the three treatments. The easy-to-use program with the excitement involved, also contributed, to the positive attitudes of the pupils. Similar results were reported by Silku (2009) who found positive attitudes towards using computers in education. Another support to this result was reported by Dhyabat (2007); Al-Dala'ah, (2003); Al-Mallah (2005); found positive attitudes to computer-based instruction.

\section{Conclusions}

This study found that the use of AI treatment mode helped pupils perform significantly better in learning music theory. It gives support to the effect of modality principle on the learning of music theory. In other words the AI treatment mode showed a significant effect on the conceptual understanding and remembering of music theory. In short, the study strongly indicated that a modality principle was effective in promoting better learning of music theory. It is suggested that modality principle be integrated into all courseware on the learning of music theory. This study found no statistical difference in the performance between pupils using TI treatment mode and pupils using AIT treatment mode. It supports the effects of redundancy principle on learning music theory. According to Mayer and Moreno (2008) redundant printed text in a multimedia presentation could overload the visual channel. The image enters the pupils' cognitive system through the eyes and is processed in the visual channel; similarly, the printed text enters through the eyes and is also processed in the visual channel. The cognitive resource in the visual channel is limited and must be shared in processing both the image and the text. This sharing results in a cognitive overload in the visual channel of the working memory. Moreover, Sweller (2005) and Moreno \& Mayer (2003) found that two sources of redundant information will result in a split-attention. This will also result in a higher cognitive load on the working memory and, therefore, impedes the learning process. Apparently, the addition of redundant audio did not improve the capacity of the working memory. Audio, text and images are important and powerful multimedia components for music theory learning. Instructional designers and music teachers need to consider and decide when and how to use these components in accordance to the modality and redundancy principles. The modality principle should be considered by the instructional designer when preparing 
multimedia music theory learning courseware for the "disadvantaged-aptitude" pupils, that is, those external locus of control, high anxiety and low music intelligence pupils. There were no significant differences in the preference or dislikes towards the three modes of courseware. Generally, all the pupils responded favorably to learning music theory using computer-based multimedia courseware.

\section{References}

Aldalalah, O. M. (2003). Educational software effects in learning musical concepts for class rooms teachers, students and their attitudes toward them. Master Thesis (Unpublished), Yarmouk University, Jordan.

Aldalalah, O. \& Fong, S. F. (2008). Effects of modality principles among Jordanian students. 2nd International Malaysian Educational Technology Convention, 5-7 November 2008, Kuantan, Malaysia. Malaysia: Malaysian Educational Technology Association.

Alherish, A., Aldalalah, O. \& Alababneh, Z. (2005). Effects of the differences of the symbolic system in instructional software on third grade students' achievement in sciences. Journal of Education Psychological Sciences, 6 (4), 13- 34.

Almalah, M. (2005). Teaching music on internet (Jordan Experience). Ph.D Thesis (Unpublished), Rooh Al Quds University, Lebanon.

Alwan, R. A. (2008). The difficulties facing music teacher in Jordan. Master Thesis (Unpublished), Yarmouk University, Jordan.

Chew, D. (2005). Computer-assisted instruction for music theory education: Rhythm in music. PhD Thesis (Unpublished), California state university.

Chandler, P. \& Sweller, J. (1991). Cognitive load theory and the format of instruction. Cognition and Instruction, 8(4), 293-332.

Clark, J. M. \& Mayer, R. (2008). E-learning and the science in instruction. San Francisco: Pfeiffer.

Clark, R. C. \& Mayer, R. E. (2003). E-Learning and the science of instruction: Pfeiffer San Francisco.

Diao, Y. \& Sweller, J. (2007). Redundancy in foreign language reading comprehension instruction: Concurrent written and spoken presentations. Learning and Instruction, 17(1), 78-88.

Dyabat, B. (2007). The effect of a computerized musical program in the achievement of Tafila Technical University students for the musical principles and their attitudes towards the program. Ph.D Thesis (Unpublished), Jordanian University.

Guderian, L. (2008). Effects of applied music composition and improvisation assignments on sight-reading ability, learning in music theory and quality in soprano recorder playing. Ph.D Thesis (Unpublished), Northwestern University.

Hamtini, S. (2002). The impact of the use of educational software influential voice in the collection of tenth grade students in the study of the basic arts education. Master Thesis (Unpublished), Yarmok University, Jordan.

Harskamp, G. E., Mayer R. E. \& Suhre, C. (2007). Does the modality principle for multimedia learning apply to science classrooms?. Learning and Instruction, 17 (5), 465-477.

Jones, T,. Clarke, V. (1994). A computer attitude scale for secondary students. Computers \& Education, 22(4) 315 -318 .

Kalyuga, S., Chandler, P. \& Sweller, J. (2004). When redundant on-screen text in multimedia technical instruction can interfere with learning. Human Factors, 46 (3), 567-581.

Kalyuga, S., Chandler, P. \& Sweller, J. (1999). Managing split-attention and redundancy in multimedia instruction. Applied Cognitive Psychology, 13(4), 351-357.

Kilic, G. B. (2001). Descriptive study of student's attitudes toward computers and attitudes toward communicating on computers in an elementary science methods course. Turkish Online Journal of Distance Education, 2 (1) Article No: 5

Mayer, R. E. (2010). Merlin c. Wittrock's enduring contributions to the science of learning. Educational Psychologist, 45(1), 46-50.

Mayer, R. E. (2001). Multimedia learning. New York, Cambridge university press.

Mayer, R. E. (2005). Cognitive theory of multimedia learning. In R. E. Mayer (Ed.), Cambridge handbook of multimedia learning (pp. 31 - 48). New York: Cambridge University Press. 
Mayer, R. E. \& Moreno, R. (1998a). A split-attention effect in multimedia learning: evidence for dual processing system in working memory. Journal of educational psychology, 90(2) 312- 320.

Mayer, R. E. \& Moreno, R. (1997). A cognitive theory of multimedia learning: Implications for design principles: Wiley, New York.

Mcvay, V. (2004). The effectiveness of color-coding for learning music theory rudiments, aural skills, and keyboard skills in persons aged in 60 and older. Ph.D Thesis (Unpublished), University of Kentucky.

Moreno, R. (2006). Does the modality principle hold for different media? A test of the method affects learning hypothesis. Journal of Computer Assisted Learning, 22(3), 149-158.

Moreno, R. \& Mayer, R. E. (1999a). Cognitive principles of multimedia learning: The role of modality and contiguity. Journal of Educational Psychology, 91(2), 358-368.

Moreno, R. \& Mayer, R. E. (2000). A coherence effect in multimedia learning: The case for minimizing irrelevant sounds in the design of multimedia instructional messages. Journal of Educational Psychology, 92(1), 117-125.

Moreno, R. \& Mayer, R. E. (2002). Verbal redundancy in multimedia learning: when reading helps listening. Journal of Educational Psychology, 94 (1), 156-163.

Mousavi, S. Y., Low, R. \& Sweller, J. (1995). Reducing cognitive load by mixing auditory and visual presentation modes. Journal of Educational Psychology, 87(2), 319-334.

Muthukumar S. L. (2005). Creating interactive multimedia-based educational courseware: cognition in learning. Springer-Verlag 7(1), 46-50.

Nosir, S. (1980). Music theory. Egypt: Dar Alsabeel.

Obeidat, R. (2003). The effects of using computers in teaching music upon tenth graders achievement. Master Thesis (Unpublished), Yarmouk University, Jordan.

Obeidat, N. (2008). Fields of using musical computer programs in teaching music. Master Thesis (Unpublished), Yarmouk University, Jordan.

Penney, C. G. (1989). Modality effects and the verbal structure of short-term verbal memory. Memory and Cognition, 17(4), 398-422.

Ramzy, S. \& Alabdaly, B. (2005). A strategy for teaching ear training courses for beginners through the use of computer programs. Journal of the Faculty of Musical Education, 12(3)23-36.

Selwyn, N. (1999) Students' attitudes towards computers in sixteen to nineteen education. Education and Information Technologies 4(2), 129-141.

Seufert, T., Schu, M. \& Nken, R. (2009). Memory characteristics and modality in multimedia learning: An aptitude treatment interaction study. Learning and Instruction, 19(1) 28-42.

Silku, A. H. (2009 February). A study on the attitudes of the faculty of communication students towards computer usage. International Conference on Educational Sciences. Nicosia, North Cyprus, 1(1), 2658-2665.

Smith, K. H. (2009). The effect of computer-assisted instruction and field independence on the development of rhythm sight-reading skills of middle school instrumental students. International Journal of Music Education, 27 (1), 59-68.

Sorden S. D. (2005). A cognitive approach to instructional design for multimedia learning. Information Science Journal, 8(1), 263-279.

Sweller, J. \& Chandler. (1994). Why some materials are difficult to learn. Cognition and Instruction, 12(3), $185-233$.

Sweller, J. (1999). Instructional design in technical areas. The Australian Council for Educational Research Ltd, Camberwell.

Sweller, J. (2005). The redundancy principle in multimedia learning. In R. E. Mayer (Ed.), The Cambridge handbook of multimedia learning. Cambridge: Cambridge University Press.

Sweller, J. (2006). Discussion of emerging topics in cognitive load research: Using learner and information characteristics in the design of powerful learning environments. Applied Cognitive Psychology, 20(2), 353-357.

Sweller, J., Paas, F. \& Renkl, A. (2003). Cognitive load theory and instructional design: recent developments. Educational Psychologist, 38(1), 1-4. 
Wilson, T. C. (2005). An implementation of a drill and practice system to assist in the teaching of basic music theory. Master Thesis (Unpublished), Brigham Young University.

Wouters, P., Paas, F., Jeroen, J. \& Merrienboer, V. (2009). Observational learning from animated models: Effects of modality and reflection on transfer. Contemporary Educational Psychology, 34(1), 1-8.

Xuanxi, L., Fong, S. F. \& Samsuddin, M. A. (2008 November). Effects of a human agent and the application of the modality principle on the learning of Chinese idioms and the attitudes among primary three students. 2nd International Malaysian Educational Technology Convention. Malaysia.

Yagmor, K. (2007). Constructing a musical training program based on cognitive and music skills components for music students at Jordanian universities, and examining the importance of its applicability. Ph.D Thesis (Unpublished), Amman Arab University for graduate Studies, Jordan.

Yagmor, K. \& Aldalalah, O. (2007). How teachers grade students acquire basic skills necessary to teach songs of the three first and attitudes toward it. Valley South University Journal, 21(2), 17-32.

Table 1. Correlation between Pre-test Scores and Post-test Scores

\begin{tabular}{llll}
\hline & & Pre-test & Post-test \\
\hline Pre-test & Pearson Correlation & 1 & $0.627^{* *}$ \\
& Sig. (2-tailed) & & 0.000 \\
& $\mathrm{~N}$ & 405 & 405 \\
\hline Post-test & Pearson Correlation & $0.627^{* *}$ & 1 \\
& Sig. (2-tailed) & 0.000 & \\
& $\mathrm{~N}$ & 405 & 405 \\
\hline
\end{tabular}

**. Correlation is significant at the 0.01 level (2-tailed).

Table 2. ANOVA of the Pre-test Scores to Measure the Equality of Groups

\begin{tabular}{cccccc}
\hline & Sum of Squares & df & Mean Square & F & Sig. \\
Between Groups & 27.038 & 2 & 13.519 & 2.349 & .097 \\
Within Groups & 2313.975 & 402 & 5.756 & & \\
Total & 2341.012 & 404 & & & \\
\hline
\end{tabular}

Table 3. Test of Homogeneity of Variances for the Variables in the Pre-test

\begin{tabular}{lllll}
\hline Variables & F & df1 & df2 & Sig. \\
\hline Treatments & .334 & 2 & 402 & .716 \\
\hline
\end{tabular}

Table 4. Testing of Normality of Distributed Pre-test

\begin{tabular}{lll}
\hline Group & Skewness & Kurtosis \\
\hline Audio and Image & .039 & .257 \\
Text and Image & .866 & .598 \\
Audio, Image and Text & .666 & .857 \\
\hline
\end{tabular}

Table 5. Test of Homogeneity of Variances for the Variables in the Post-test

\begin{tabular}{lllll}
\hline Variables & F & df1 & df2 & Sig. \\
\hline Treatments & .620 & 2 & 402 & .303 \\
\hline
\end{tabular}


Table 6. Testing of Normality of Distributed Post-test

\begin{tabular}{lcc}
\hline Group & Skewness & Kurtosis \\
\hline Audio and Image & $-.193-$ & $-1.044-$ \\
Text and Image & .906 & .991 \\
Audio, Image and Text & .906 & 1.137 \\
\hline
\end{tabular}

Table 7. Post-test Scores of Pupils in Various Treatment Groups

\begin{tabular}{cccc}
\hline Groups & Mean & Std. Deviation & $\mathrm{N}$ \\
\hline AI & 25.1719 & 3.35817 & 128 \\
TI & 16.8227 & 3.77072 & 141 \\
AIT & 16.6397 & 4.33534 & 136 \\
Total & 19.4000 & 5.49464 & 405 \\
\hline
\end{tabular}

Table 8. ANCOVA of the Post-test Scores of Pupils in Various Treatment Groups

\begin{tabular}{llllll}
\hline Source & Type III Sum of Squares & df & Mean Square & F & Sig. \\
\hline Corrected Model & $9992.351^{\mathrm{a}}$ & 3 & 3330.784 & 605.776 & .000 \\
Intercept & 1037.321 & 1 & 1037.321 & 188.659 & .000 \\
pre-test & 3755.283 & 1 & 3755.283 & 682.980 & .000 \\
Groups & 5201.347 & 2 & 2600.673 & 472.989 & .000 \\
Error & 2204.849 & 401 & 5.498 & & \\
Total & 164623.000 & 405 & & & \\
Corrected Total & 12197.200 & 404 & & & \\
\hline
\end{tabular}

a. R Squared $=.819($ Adjusted R Squared $=.818)$

Table 9. Summary of Post Hoc Pairwise Comparisons

\begin{tabular}{|c|c|c|c|c|}
\hline (I) Group & (J) Group & $\begin{array}{c}\text { Mean Difference } \\
(\mathrm{I}-\mathrm{J})\end{array}$ & Std. Error & Sig. ${ }^{\text {a }}$ \\
\hline \multirow[t]{2}{*}{ AI } & TI & $7.751^{*}$ & .287 & .000 \\
\hline & AIT & $7.749^{*}$ & .290 & .000 \\
\hline \multirow[t]{2}{*}{ TI } & AI & $-7.751^{*}$ & .287 & .000 \\
\hline & AIT & $-.002-$ & .282 & .994 \\
\hline \multirow[t]{2}{*}{ AIT } & $\mathrm{AI}$ & $-7.749^{*}$ & .290 & .000 \\
\hline & TI & .002 & .282 & .994 \\
\hline
\end{tabular}

Table 10. t-test of Attitude Scores of Pupils in Various Treatment Groups

\begin{tabular}{cccccccc}
\hline Dependent Variable & Group & N & Mean & Std. Deviation & t & df & $\begin{array}{c}\text { Sig. } \\
\text { (2-tailed) }\end{array}$ \\
\hline Attitudes towards & AI & 128 & 37.7891 & 7.10623 & $-.324-$ & & 0.270 \\
Musical Instructional & TI & 141 & 38.0567 & 6.46173 & & 267 & 0.655 \\
\cline { 2 - 7 } Computerized & TI & 141 & 38.0567 & 6.46173 & & 275 & $0.613-$ \\
Program & AIT & 136 & 38.5294 & 6.36418 & 278 \\
\hline
\end{tabular}




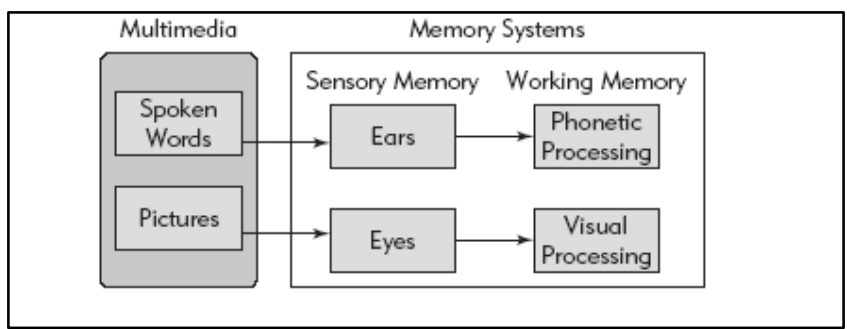

Figure 1. Modality Principle (Mayer \& Moreno, 1998)

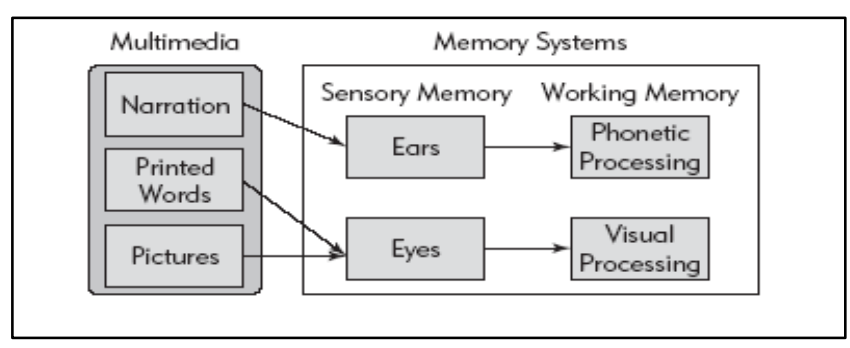

Figure 2. Redundancy Principles (Mayer, 2001) 